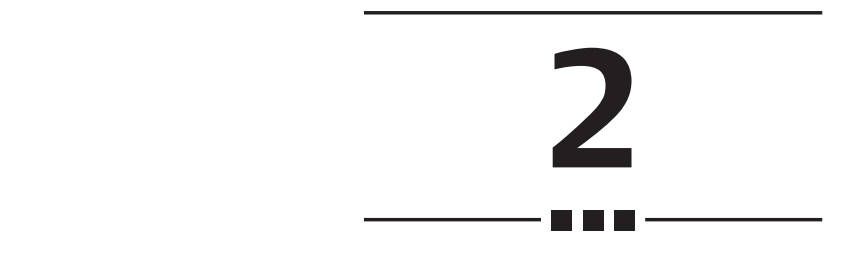

\title{
Clearing Cervical Spine Injuries: MRI, Dynamic X-rays, CT
}

\author{
ANTHONY S. LAPINSKY AND MARK S. ESKANDER
}

Cervical spine injury patients require careful evaluation to prevent further morbidity due to apparent and hidden injuries. Systematic evaluation including injury history, physical examination, and imaging studies helps to prevent complications from missed injuries. Awake and alert patients who have negative exam findings do not require further evaluation. When utilized appropriately, cervical spine evaluation algorithms have decreased the morbidity for injured patients. ${ }^{1-3}$

Cervical collars should be removed as soon as feasible after trauma. As soon as an injury has been excluded, the collar should be discontinued to decrease collar-associated morbidity. Some examples of morbidity associated with collar use are decubitus ulceration ${ }^{4-6}$ and increased intracranial pressure (ICP). ${ }^{7,8}$ Increased duration of mechanical ventilation, longer intensive care unit (ICU) and hospital stays, and increased incidence of delirium and pneumonia were also associated with collar use. ${ }^{9}$

Radiographic evaluation with plain x-rays, dynamic $\mathrm{x}$ rays, computed tomography, and magnetic resonance imaging (MRI) in a systematic manner minimizes the chance for undetected occult injury. In turn, this decreases additional patient morbidity. The end point in evaluation of these injuries is the detection or exclusion of significant injury to the cervical spine. MRI has been especially touted for the ability to detect ligament and disk injury in the face of normal radiographic and CT studies. Significant injury is that which requires ongoing treatment, either with immobilization or with surgery. Clearing the cervical spine of injury is a critical phase in the treatment of polytrauma patients to further the treatment process and prevent morbidity associated with immobilization. ${ }^{10}$ Clearance is best defined as the exclusion of significant injury, and this allows discontinuation of immobilization and precautions, better pulmonary care, and easier ancillary care.
In the past, practice guidelines based on clinical experience have led to better detection rates of injury and hence improved patient care. The development of evaluation protocols based on best evidence medicine and the increased access to advanced imaging studies (especially CT) has paralleled the improvement in patient care. ${ }^{1}$ In general, CT has become a frontline tool in the evaluation of blunt trauma and cervical spine injury, often supplanting the need for plain radiographs. ${ }^{11}$

A comprehensive review of the literature included a search of the Medline database and a review of the references of relevant review articles. The best evidence for the use of advanced radiographic imaging studies for evaluation of cervical spine injuries was chosen from the search (Table 2.1). For evaluation of MRI in clearance of the cervical spine, three level I studies were identified and one metaanalysis. Three level II studies of the use of MRI were also identified. Two level III studies comparing dynamic x-ray versus CT where identified: one relying on upright (gravity

Table 2.1 Evidence of Published Studies

\begin{tabular}{|c|c|c|}
\hline Level & $\begin{array}{l}\text { Number } \\
\text { of Studies }\end{array}$ & Study Type \\
\hline I & 4 & $\begin{array}{l}\text { Testing of previously developed } \\
\text { diagnostic criteria in series of } \\
\text { consecutive patients (with universally } \\
\text { applied reference gold standard) }{ }^{12,13,25} \\
\text { Systematic review of level I studies }{ }^{14}\end{array}$ \\
\hline II & 7 & $\begin{array}{l}\text { Development of diagnostic criteria on } \\
\text { the basis of consecutive patients (with } \\
\text { universally applied reference gold } \\
\text { standard) }\end{array}$ \\
\hline III & 14 & $\begin{array}{l}\text { Study of nonconsecutive patients } \\
\text { (without consistently applied reference } \\
\text { gold standard) })^{20-24,27-33}\end{array}$ \\
\hline
\end{tabular}


added) x-ray and the other manual flexion and extension range of motion x-rays. Lastly, the efficacy of CT to detect the extent of injury is well described in multiple level III retrospective comparative studies versus both plain $\mathrm{x}$-ray and MRI.

\section{Magnetic Resonance Imaging}

\section{Level I Studies}

There are two level I prospective diagnostic protocols utilizing MRI in the clearance of cervical spine injuries. Clinically nonevaluable patients without demonstrable neurological injury or deficit were evaluated with an MRI scan after a normal CT scan or an X-ray.

Benzel et al $^{12}$ reported on 174 patients of whom 62 were found to have abnormal findings on MRI. Two of those patients underwent operative stabilization treatment, and the others were treated with cervical orthoses. All of these patients had stable flexion-extension radiographs at 1 to 3 months follow-up. The negative MRI patients had their prophylactic cervical immobilization discontinued after the negative scan. No complications were noted in the cohort at final follow-up. The negative predictive value (NPV) for MRI was $100 \%$, and there were no falsenegatives.

Schuster et $\mathrm{al}^{13}$ reported on 120 patients who were obtunded but without apparent clinical neurological injury. All patients had a normal X-ray or CT scan and persistent neck pain or significant mechanism for injury. Fifteen patients were treated in a cervical collar for soft tissue injury noted on their MRI scan, and the remaining 105 patients with normal MRI scans had their cervical collar removed. Final follow-up revealed no complications. Again, the NPV was $100 \%$, and there were no false-negatives.

Muchow at $\mathrm{al}^{14}$ performed a meta-analysis in studies all with greater than 30 patients. Inclusion and exclusion criteria were homogeneous, and imaging (MRI) studies were performed within 72 hours in three studies, in less than 48 hours in two studies, and within 24 hours in the final study. Overall, a normal MRI had an NPV of $100 \%$, allowing discontinuation of immobilization in a timely manner.

\section{Level II Studies}

Albrecht et al $^{15}$ described a retrospective study of 48 patients who were obtunded and underwent MRI after a negative $\mathrm{x}$-ray and/or CT scan. A positive MRI was found in 27 patients. Twenty-one patients had a normal MRI scan and went on without complications. No false-negatives and an NPV of $100 \%$ were reported. However, poor follow-up (41\%) was a deficiency of this study.
D'Alise et al $^{16}$ reported on 121 intubated patients who had cervical injury risk factors and a normal CT scan. Patients were excluded if they had abnormal x-ray findings, a CT abnormality, or evidence of neurological injury. Thirty-one patients had abnormal MRI scans, and eight underwent surgical stabilization; 23 others were lost to follow-up. Ninety patients had normal MRI scans, and the collar was removed. In addition, flexion and extension x-rays in these 90 patients were also normal. No false-negatives were found, and the NPV for MRI was $100 \%$.

Keiper et $\mathrm{al}^{17}$ treated 52 patients for whom MRI was obtained after CT disclosed no abnormality and question of injury remained. The MRI scan was abnormal in 16 patients, and four underwent operation; the others were treated with an orthosis. For those 36 patients with normal MRI, the collar was discontinued, and follow-up revealed no abnormalities. Again, there were no false-negatives, and the NPV was $100 \%$.

Como at al $^{18}$ reported a prospective evaluation of 115 obtunded patients with a negative CT scan for acute cervical trauma in whom MRI of the cervical spine was subsequently obtained. Six injuries were identified on MRI, but no management changes occurred. Complications from cervical collar use in six patients occurred, but no complications due to transport or image acquisition occurred. Significant cost savings by eliminating the cervical spine MRI were estimated at $\$ 250,000$. The authors concluded that for patients with negative cervical spine CT, MRI did not affect the treatment plan and may be unnecessary.

Platzer et $\mathrm{al}^{19}$ reported diagnostic criteria for the use of MRI to avoid a delay in diagnosis. Prospective patient evaluation was retrospectively analyzed for 118 patients. CT was most efficient in detecting skeletal injuries with a sensitivity of $100 \%$. MRI was necessary to detect significant ligament injuries in $6 \%$ of patients.

\section{Level III Studies}

Holmes et $\mathrm{al}^{20}$ confirmed that MRI is superior at identifying spinal cord injury (SCI) and ligamentous injury and CT was better at significant bone injury detection.

Hogan et $\mathrm{al}^{21}$ described a group of patients for whom a follow-up MRI scan was negative, which correlated with an initial negative CT scan.

Stassen et $\mathrm{al}^{22}$ described a high percentage of obtunded patients (25\%) with ligamentous injuries detected by MRI, but none required treatment beyond immobilization.

Sarani et al ${ }^{23}$ described a group of 46 obtunded patients with a normal CT scan of whom five had abnormal MRI results (four ligamentous and one herniated nucleus pulposis [HNP]); with the four ligamentous injuries treated with an orthosis for 6 weeks.

In patients with negative MRI findings for whom previous studies were inconclusive or negative for osseous injury, Horn et $\mathrm{al}^{24}$ recommended clearance of the cervical spine. 


\section{Computed Tomography}

\section{Level I Studies}

Schenarts et $\mathrm{al}^{25}$ prospectively compared CT to plain x-ray in 1356 patients with altered mental status. In 70 patients, 95 injuries to the upper cervical spine were identified. Plain radiographs failed to identify $45 \%$ of the cervical spine injuries.

\section{Level II Studies}

A retrospective cohort study was reported by Harris et $\mathrm{al}^{26}$ to determine the frequency of injuries missed by initial CT of the cervical spine in 367 obtunded blunt trauma patients. The CT scan had an NPV of $99.7 \%$. Only one patient out of 367 patients was eventually found to have an initially undetected injury through additional imaging. This patient had a cervical spinal cord contusion associated with posterior ligament injury and underwent no further treatment. In this study, the addition of an upright cervical spine radiograph used to test dynamic stability did not identify any further injuries. The only additional injury identified was found by clinical examination with impaired sensorimotor function with a confirmatory MRI scan, which revealed a posterior ligament injury and spinal cord contusion. The delay to obtain an upright cervical spine radiograph in the obtunded patient was 2.6 days after the initial CT scan.

Cooper and Ackland ${ }^{3}$ performed a retrospective review at Alfred Hospital in Melbourne, Australia, demonstrating the superiority of CT imaging alone over plain x-rays, adjunctive dynamic flexion-extension x-rays, and MRI scanning in their trauma population. They reported that up to $16 \%$ of cervical spine injuries were missed by plain $\mathrm{x}$-rays alone, which is similar to other reports in the literature. ${ }^{3,11,19}$ There were no additional unstable injuries identified when dynamic flexion-extension x-rays were utilized when compared with injuries identified with helical CT reconstructions. Based on logistic concerns, such as complex transport requirements and image acquisition time, there were no advantages of MRI in detecting cervical disk and ligamentous injuries.

\section{- Dynamic Plain X-rays}

\section{Level I Studies}

There are no level I studies available.

\section{Level II Studies}

There are no level II studies available.

\section{Level III Studies}

In another study from the Alfred Hospital, Padayachee et $\mathrm{al}^{27}$ studied the optimal protocol for clearing the cervical spine in unconscious patients with traumatic brain injury. The study included 276 unconscious patients who underwent plain $\mathrm{x}$-ray, CT scanning with three-dimensional (3-D) reconstructions, and dynamic flexion-extension $\mathrm{x}$ rays with fluoroscopy. Radiographic reports from a prospective ICU database were reviewed and were the focus of this study. The dynamic flexion-extension x-rays performed with fluoroscopy identified no new fractures or instability. False-negative results occurred in one patient on flexion-extension views, and false-positive results occurred in six patients. Dynamic flexion-extension x-rays were inadequate in nine patients. No injuries were identified as a consequence of performing dynamic flexion-extension $\mathrm{x}$-rays.

Spiteri et $\mathrm{al}^{28}$ found no advantage of dynamic cervical screening to helical CT in spinal clearance, and due to its redundancy, have abandoned its routine use.

Platzer et $\mathrm{al}^{19}$ presented a comprehensive cervical spine imaging protocol to avoid unnecessary delays in the diagnosis of cervical injury. A spiral CT scan showed a sensitivity of $100 \%$ for detection of skeletal injury while a single cross-table lateral view x-ray achieved only a 63\% sensitivity. Functional radiography and an MRI scan detected a significant ligamentous injury in $6 \%$ of patients. By utilizing their CT scan protocol, a delay in diagnosis was avoided.

Additionally, Anglen et al $^{29}$ reported that, although flexionextension $\mathrm{x}$-rays are commonly inadequate, when properly performed, they have a high NPV. Griffiths et $\mathrm{al}^{30}$ reported that $59 \%$ of flexion-extension studies were inadequate and that this, combined with a lack of cost-effectiveness, was the reason that use of this screening exam was discontinued for obtunded trauma patients. Bolinger et $\mathrm{al}^{31}$ concluded that bedside flexion-extension radiographs should no longer be utilized in the clearance of comatose patients due to the high number of inadequate studies. Insko et $\mathrm{al}^{32}$ reported $30 \%$ of flexion-extension radiographs inadequate, but when no limits to range of motion (ROM) on physical exam were present, the false-negative rate was zero. Strict adherence to fluoroscopy protocol must be followed because Davis et $\mathrm{al}^{33}$ reported the complication of quadriplegia in one patient for whom a strict protocol was violated.

\section{Pearls}

- Level I, II, and III evidence suggests an exclusion of plain x-ray for the evaluation of suspected cervical spine injuries. The initial tool should be CT scan. As a secondary study, MRI can be used for definitive clearing of cervical spines. The obtunded patient with a normal CT scan and suspected injury is still a controversial area. 


\section{Summary of Data}

The literature suggests that MRI is highly sensitive in the detection of injury in the cervical spine, with a very high NPV. CT also appears to be a highly effective screening tool, with very few injuries undetected with this modality, especially when compared with plain radiographs. ${ }^{11} \mathrm{CT}$ of the cervical spine requires little extra time when added to a CT scan of the head during the initial trauma evaluation, and detection rates are very high. ${ }^{34-36}$ Those injuries that are not found on plain $\mathrm{x}$ ray and CT appear to be detectable by MRI, and the true clinical significance of some of those detected injuries appears to be low, given the small numbers identified and even smaller percentage of patients requiring intervention to address those findings..$^{37}$ The studies are summarized in Table 2.2 .

Utilizing MRI to identify significant ligament and disk injuries impacts patients significantly given its high NPV. If the MRI scan is normal, significant injury is not likely present. Within the meta-analysis presented, only 15 patients in the cohort of 515 sustained injuries for which surgery was recommended. Although only $3 \%$ of patients were recommended for surgery based on MRI findings, the importance of a negative MRI in preventing unnecessary treatment is the greatest strength of MRI. ${ }^{10}$

\section{- Consensus Statements}

The Eastern Association for the Surgery of Trauma (EAST) guidelines are derived from level II and III evidence and EAST panel members' clinical opinion (level V evidence). ${ }^{1}$ The EAST guidelines are the basis for many cervical spine immobilization practice guidelines and have recently undergone revision and updating from the approach of evidence-based medicine. The major shift has been the exclusion of plain $\mathrm{x}$-ray for the evaluation of suspected cervical spine injuries, supplanted by CT. MRI is placed as an adjunctive study at the discretion of the treating institution. The nebulous scenario remains the obtunded patient with a normal CT scan and suspected injury.

\section{Summary of Eastern Association for the Surgery of Trauma Practice Guidelines: 2009 Update: Identifying Cervical Spine Injuries Following Trauma}

A. Removal of cervical collars:

1. Collars should be removed as soon as feasible after trauma.

2. In the patient with penetrating trauma to the brain: Immobilization in a cervical collar is not necessary unless the trajectory suggests direct injury to the cervical spine (CS).

3. In awake, alert trauma patients without neurological deficit or distracting injury and without neck pain or tenderness and with full range of motion of the CS: CS imaging is not necessary and the cervical collar may be removed.

4. All other patients in whom CS injury is suspected must have radiographic evaluation. This applies to patients with pain or tenderness, patients with neurological deficit, patients with altered mental status, and patients with distracting injury.

B. Imaging

1. Primary screening is axial computed tomography (CT) from occiput to T1 with sagittal and coronal reconstructions.

2. Plain radiographs should not be obtained.

C. If CT of the CS demonstrates injury:

1. Obtain a spine consultation.

D. If there is neurological deficit attributable to a CS injury:

1. Obtain a spine consultation.

2. Obtain an MRI scan.

E. Options for the neurologically intact awake and alert patient complaining of neck pain with a negative CT scan: 1. Continue the cervical collar.

2. The cervical collar may be removed after a negative MRI scan.

3. The cervical collar may be removed after negative and adequate flexion-extension films (level III).

F. For the obtunded patient with a negative CT scan and gross motor function of the extremities:

1. Flexion-extension radiography should not be performed.

2. The risk:benefit ratio of obtaining an MRI scan in addition to CT is not clear, and its use must be individualized in each institution.

G. Options are as follows:

1. Continue cervical collar immobilization until a clinical exam can be performed.

2. Remove the cervical collar on the basis of CT alone.

3. Obtain an MRI scan.

4. If the MRI scan is negative, the cervical collar may be safely removed.

\section{- Conclusions}

As described in the original translation to English, The Hippocratic Oath states:

I will prescribe regimens for the good of my patients according to my ability and my judgment and never do harm to anyone. ${ }^{38}$

Guidelines for treatment of injury utilizing evidence-based medicine are a prerequisite based on the sworn intentions of all physicians and surgeons. The protocols for transport and evaluation of injured patients reflect these standards. The combination of physical exam, CT scan, and MRI scan enables the modern-day physician to gather individual patient data on which to guide patients through appropriate treatment. 
Table 2.2 Summary of Data Regarding Comparison of MRI, CT, and Plain Radiographs for Detecting Cervical Spine Injuries

\begin{tabular}{|c|c|c|c|}
\hline Study & Level & Imaging & Findings \\
\hline $\begin{array}{l}\text { Benzel } \\
\text { et al }{ }^{12}\end{array}$ & I & MRI & $\begin{array}{l}\text { The NPV for MRI was } 100 \% \text {, } \\
\text { and there were no false- } \\
\text { negatives. }\end{array}$ \\
\hline $\begin{array}{l}\text { Schuster } \\
\text { et al }{ }^{13}\end{array}$ & I & $\begin{array}{l}\text { MRI, CT, } \\
\text { x-ray }\end{array}$ & $\begin{array}{l}\text { The NPV was } 100 \% \text {, and there } \\
\text { were no false- } \\
\text { negatives. }\end{array}$ \\
\hline $\begin{array}{l}\text { Muchow } \\
\text { et al }^{14}\end{array}$ & I & MRI & $\begin{array}{l}\text { A normal MRI had an NPV } \\
\text { of } 100 \% \text {, allowing } \\
\text { discontinuation of } \\
\text { immobilization in a timely } \\
\text { manner. }\end{array}$ \\
\hline $\begin{array}{l}\text { Schenarts } \\
\text { et al }\end{array}$ & I & CT, x-ray & $\begin{array}{l}\text { In } 70 \text { patients, } 95 \text { injuries to } \\
\text { the upper cervical spine } \\
\text { were identified. Plain } \\
\text { radiographs failed to } \\
\text { identify } 45 \% \text { of the } \\
\text { cervical spine injuries. }\end{array}$ \\
\hline $\begin{array}{l}\text { Cooper } \\
\text { et } \mathrm{al}^{3}\end{array}$ & II & $\begin{array}{l}\text { MRI, CT, } \\
\text { x-ray }\end{array}$ & $\begin{array}{l}\text { A retrospective review } \\
\text { demonstrating the } \\
\text { superiority of } C T \text { imaging } \\
\text { alone over plain x-rays, } \\
\text { adjunctive dynamic } \\
\text { flexion-extension x-rays, } \\
\text { and MRI scanning in their } \\
\text { trauma population. }\end{array}$ \\
\hline $\begin{array}{l}\text { Gale } \\
\text { et al }{ }^{11}\end{array}$ & II & $\begin{array}{l}\text { MRI, CT, } \\
\text { x-ray }\end{array}$ & $\begin{array}{l}\text { In general, CT scan has } \\
\text { become a frontline tool } \\
\text { in the evaluation of blunt } \\
\text { trauma and cervical spine } \\
\text { injury, often supplanting } \\
\text { the need for plain } \\
\text { radiographs. }\end{array}$ \\
\hline $\begin{array}{l}\text { Albrecht } \\
\text { et al }^{15}\end{array}$ & II & $\begin{array}{l}\text { MRI, CT, } \\
\text { x-ray }\end{array}$ & $\begin{array}{l}\text { No false-negatives and an } \\
\text { NPV of } 100 \% \text { were reported. }\end{array}$ \\
\hline $\begin{array}{l}\text { D'Alise } \\
\text { et al }{ }^{16}\end{array}$ & II & $\begin{array}{l}\text { MRI, CT, } \\
\text { x-ray }\end{array}$ & $\begin{array}{l}\text { No false-negatives were } \\
\text { found, and the NPV for } \\
\text { MRI was } 100 \% \text {. }\end{array}$ \\
\hline $\begin{array}{l}\text { Keiper } \\
\text { et al }\end{array}$ & II & MRI, CT & $\begin{array}{l}\text { MRI showed no false- } \\
\text { negatives, and the NPV } \\
\text { was } 100 \% \text {. }\end{array}$ \\
\hline $\begin{array}{l}\text { Como } \\
\text { et al }\end{array}$ & II & MRI, CT & $\begin{array}{l}\text { For patients with negative } \\
\text { cervical spine CT, MRI did } \\
\text { not affect the treatment } \\
\text { plan and may be } \\
\text { unnecessary. }\end{array}$ \\
\hline $\begin{array}{l}\text { Platzer } \\
\text { et al }{ }^{19}\end{array}$ & II & MRI, CT & $\begin{array}{l}\text { CT scan showed a } \\
\text { sensitivity of } 100 \% \text { for } \\
\text { detection of skeletal injury. } \\
\text { MRI scan detected a } \\
\text { significant ligamentous } \\
\text { injury in } 6 \% \text { of patients. }\end{array}$ \\
\hline $\begin{array}{l}\text { Harris } \\
\text { et al }\end{array}$ & II & MRI, CT & $\begin{array}{l}\text { CT scan had an NPV of } 99.7 \% \text {. } \\
\text { The only additional injury } \\
\text { identified was found by } \\
\text { clinical examination with } \\
\text { impaired sensorimotor } \\
\text { function with confirmatory } \\
\text { MRI scan. }\end{array}$ \\
\hline $\begin{array}{l}\text { Holmes } \\
\text { et al }\end{array}$ & III & MRI, CT & $\begin{array}{l}\text { MRI is superior at identifying } \\
\text { spinal cord injury and } \\
\text { ligamentous injury and CT } \\
\text { was better at significant } \\
\text { bone injury detection. }\end{array}$ \\
\hline $\begin{array}{l}\text { Hogan } \\
\text { et al }\end{array}$ & III & MRI, CT & $\begin{array}{l}\text { Follow-up MRI was } \\
\text { negative, which correlated } \\
\text { with an initial negative CT. }\end{array}$ \\
\hline
\end{tabular}

Table 2.2 (continued)

\begin{tabular}{|c|c|c|c|}
\hline Study & Level & Imaging & Findings \\
\hline $\begin{array}{l}\text { Stassen } \\
\text { et } \mathrm{al}^{22}\end{array}$ & III & MRI & $\begin{array}{l}\text { 25\% with ligamentous } \\
\text { injuries detected by MRI. }\end{array}$ \\
\hline $\begin{array}{l}\text { Sarani } \\
\text { et } \mathrm{al}^{23}\end{array}$ & III & MRI, CT & $\begin{array}{l}46 \text { obtunded patients with } \\
\text { normal CT of whom five } \\
\text { had abnormal MRIs. }\end{array}$ \\
\hline Horn et a $\left.\right|^{24}$ & III & MRI & $\begin{array}{l}\text { Recommended that cervical } \\
\text { spine clearance can be } \\
\text { accomplished with a } \\
\text { negative MRI in the setting } \\
\text { of other negative or } \\
\text { inconclusive studies. }\end{array}$ \\
\hline $\begin{array}{l}\text { Padayachee } \\
\text { et a }\left.\right|^{27}\end{array}$ & III & CT, x-ray & $\begin{array}{l}\text { The dynamic flexion- } \\
\text { extension x-rays performed } \\
\text { with fluoroscopy identified } \\
\text { no new fractures or } \\
\text { instability. False-negative } \\
\text { results occurred in one } \\
\text { patient on flexion-extension } \\
\text { views, and false-positive } \\
\text { results occurred in six } \\
\text { patients. Dynamic flexion- } \\
\text { extension x-rays were } \\
\text { inadequate in nine patients. } \\
\text { No injuries were identified } \\
\text { as a consequence of } \\
\text { performing dynamic } \\
\text { flexion-extension x-rays. }\end{array}$ \\
\hline $\begin{array}{l}\text { Spiteri } \\
\text { et al }\end{array}$ & III & $\mathrm{CT}$ & $\begin{array}{l}\text { No advantage of dynamic } \\
\text { cervical screening to } \\
\text { helical CT }\end{array}$ \\
\hline $\begin{array}{l}\text { Anglen } \\
\text { et al }{ }^{29}\end{array}$ & III & x-ray & $\begin{array}{l}\text { Flexion-extension x-rays have } \\
\text { a high NPV. }\end{array}$ \\
\hline $\begin{array}{l}\text { Griffiths } \\
\text { et al }{ }^{30}\end{array}$ & III & x-ray & $\begin{array}{l}59 \% \text { of flexion-extension } \\
\text { studies were inadequate }\end{array}$ \\
\hline $\begin{array}{r}\text { Bolinger } \\
\text { et }^{31}{ }^{31}\end{array}$ & III & $x$-ray & $\begin{array}{l}\text { High number of } \\
\text { inadequate studies }\end{array}$ \\
\hline $\begin{array}{l}\text { Insko } \\
\text { et } \mathrm{al}^{32}\end{array}$ & III & $x$-ray & $\begin{array}{l}30 \% \text { of flexion-extension } \\
\text { radiographs inadequate }\end{array}$ \\
\hline $\begin{array}{l}\text { Davis } \\
\quad \text { et } \text { al }^{33}\end{array}$ & III & $x$-ray & $\begin{array}{l}\text { Complication of } \\
\text { quadriplegia with flexion- } \\
\text { extension }\end{array}$ \\
\hline
\end{tabular}

Abbreviations: CT, computed tomography; MRI, magnetic resonance imaging; NPV, negative predictive value.

A majority of injuries can be detected and definitively evaluated in a timely fashion by CT. Further evaluation by MRI can detect most additional injuries.

One's own ability is a combination of aptitude, intelligence, and skill as applied to the learned prior experience-the basis of expert opinion. Judgment is the considered evaluation of evidence in the formation of making a decision. Never doing harm is the art of medicine.

The combination of CT, MRI, and evidence-based medicine provides physicians with a solid foundation to uphold their oath.

\section{References}

1. Pasquale M, Fabian TC. Practice management guidelines for trauma from the Eastern Association for the Surgery of Trauma. J Trauma 1998;44:941-956, discussion 956-957 
2. Stiell IG, Clement CM, McKnight RD, et al. The Canadian C-spine rule versus the NEXUS low-risk criteria in patients with trauma. N Engl J Med 2003;349:2510-2518

3. Cooper DJ, Ackland HM. Clearing the cervical spine in unconscious head injured patients: the evidence. Crit Care Resusc 2005; 7:181-184

4. Ackland HM, Cooper DJ, Cooper JD, Malham GM, Kossmann T. Factors predicting cervical collar-related decubitus ulceration in major trauma patients. Spine (Phila Pa 1976) 2007;32:423-428

5. Chendrasekhar A, Moorman DW, Timberlake GA. An evaluation of the effects of semirigid cervical collars in patients with severe closed head injury. Am Surg 1998;64:604-606

6. Powers J, Daniels D, McGuire C, Hilbish C. The incidence of skin breakdown associated with use of cervical collars. J Trauma Nurs 2006;13:198-200

7. Hunt K, Hallworth S, Smith M. The effects of rigid collar placement on intracranial and cerebral perfusion pressures. Anaesthesia 2001;56:511-513

8. Mobbs RJ, Stoodley MA, Fuller J. Effect of cervical hard collar on intracranial pressure after head injury. ANZ J Surg 2002;72: 389-391

9. Stelfox HT, Velmahos GC, Gettings E, Bigatello LM, Schmidt U. Computed tomography for early and safe discontinuation of cervical spine immobilization in obtunded multiply injured patients. J Trauma 2007;63:630-636

10. Webber-Jones JE, Thomas CA, Bordeaux RE Jr. The management and prevention of rigid cervical collar complications. Orthop Nurs 2002;21:19-25, quiz 25-27

11. Gale SC, Gracias VH, Reilly PM, Schwab CW. The inefficiency of plain radiography to evaluate the cervical spine after blunt trauma. J Trauma 2005;59:1121-1125

12. Benzel EC, Hart BL, Ball PA, Baldwin NG, Orrison WW, Espinosa MC. Magnetic resonance imaging for the evaluation of patients with occult cervical spine injury. J Neurosurg 1996;85: 824-829

13. Schuster R, Waxman K, Sanchez B, et al. Magnetic resonance imaging is not needed to clear cervical spines in blunt trauma patients with normal computed tomographic results and no motor deficits. Arch Surg 2005;140:762-766

14. Muchow RD, Resnick DK, Abdel MP, Munoz A, Anderson PA. Magnetic resonance imaging (MRI) in the clearance of the cervical spine in blunt trauma: a meta-analysis. J Trauma 2008;64: 179-189

15. Albrecht RM, Kingsley D, Schermer CR, Demarest GB, Benzel EC, Hart BL. Evaluation of cervical spine in intensive care patients following blunt trauma. World J Surg 2001;25:1089-1096

16. D'Alise MD, Benzel EC, Hart BL. Magnetic resonance imaging evaluation of the cervical spine in the comatose or obtunded trauma patient. J Neurosurg 1999;91(1, Suppl):54-59

17. Keiper MD, Zimmerman RA, Bilaniuk LT. MRI in the assessment of the supportive soft tissues of the cervical spine in acute trauma in children. Neuroradiology 1998;40:359-363

18. Como JJ, Thompson MA, Anderson JS, et al. Is magnetic resonance imaging essential in clearing the cervical spine in obtunded patients with blunt trauma? J Trauma 2007;63:544-549

19. Platzer P, Jaindl M, Thalhammer G, et al. Clearing the cervical spine in critically injured patients: a comprehensive C-spine protocol to avoid unnecessary delays in diagnosis. Eur Spine J 2006;15:1801-1810

20. Holmes JF, Mirvis SE, Panacek EA, Hoffman JR, Mower WR, Velmahos GC; NEXUS Group. Variability in computed tomography and magnetic resonance imaging in patients with cervical spine injuries. J Trauma 2002;53:524-529, discussion 530

21. Hogan GJ, Mirvis SE, Shanmuganathan K, Scalea TM. Exclusion of unstable cervical spine injury in obtunded patients with blunt trauma: is MR imaging needed when multi-detector row CT findings are normal? Radiology 2005;237:106-113

22. Stassen NA, Williams VA, Gestring ML, Cheng JD, Bankey PE. Magnetic resonance imaging in combination with helical computed tomography provides a safe and efficient method of cervical spine clearance in the obtunded trauma patient. J Trauma 2006;60:171-177

23. Sarani B, Waring S, Sonnad S, Schwab CW. Magnetic resonance imaging is a useful adjunct in the evaluation of the cervical spine of injured patients. J Trauma 2007;63:637-640

24. Horn EM, Lekovic GP, Feiz-Erfan I, Sonntag VK, Theodore N. Cervical magnetic resonance imaging abnormalities not predictive of cervical spine instability in traumatically injured patients. Invited submission from the Joint Section Meeting on Disorders of the Spine and Peripheral Nerves, March 2004. J Neurosurg Spine 2004;1:39-42

25. Schenarts PJ, Diaz J, Kaiser C, Carrillo Y, Eddy V, Morris JA Jr. Prospective comparison of admission computed tomographic scan and plain films of the upper cervical spine in trauma patients with altered mental status. J Trauma 2001;51:663-668, discussion 668-669

26. Harris TJ, Blackmore CC, Mirza SK, Jurkovich GJ. Clearing the cervical spine in obtunded patients. Spine (Phila Pa 1976) 2008;33:1547-1553

27. Padayachee L, Cooper DJ, Irons S, et al. Cervical spine clearance in unconscious traumatic brain injury patients: dynamic flexion-extension fluoroscopy versus computed tomography with three-dimensional reconstruction. J Trauma 2006;60: 341-345

28. Spiteri V, Kotnis R, Singh P, et al. Cervical dynamic screening in spinal clearance: now redundant. J Trauma 2006;61:11711177, discussion 1177

29. Anglen J, Metzler M, Bunn P, Griffiths H. Flexion and extension views are not cost-effective in a cervical spine clearance protocol for obtunded trauma patients. J Trauma 2002;52:54-59

30. Griffiths HJ, Wagner J, Anglen J, Bunn P, Metzler M. The use of forced flexion/extension views in the obtunded trauma patient. Skeletal Radiol 2002;31:587-591

31. Bolinger B, Shartz M, Marion D. Bedside fluoroscopic flexion and extension cervical spine radiographs for clearance of the cervical spine in comatose trauma patients. J Trauma 2004;56: 132-136

32. Insko EK, Gracias VH, Gupta R, Goettler CE, Gaieski DF, Dalinka MK. Utility of flexion and extension radiographs of the cervical spine in the acute evaluation of blunt trauma. J Trauma 2002;53:426-429

33. Davis JW, Kaups KL, Cunningham MA, et al. Routine evaluation of the cervical spine in head-injured patients with dynamic fluoroscopy: a reappraisal. J Trauma 2001;50:1044-1047

34. Freedman I, van Gelderen D, Cooper DJ, et al. Cervical spine assessment in the unconscious trauma patient: a major trauma service's experience with passive flexion-extension radiography. J Trauma 2005;58:1183-1188

35. Hanson JA, Blackmore CC, Mann FA, Wilson AJ. Cervical spine injury: a clinical decision rule to identify high-risk patients for helical CT screening. AJR Am J Roentgenol 2000;174:713-717

36. Barba CA, Taggert J, Morgan AS, et al. A new cervical spine clearance protocol using computed tomography. J Trauma 2001;51:652-656, discussion 656-657

37. Kihiczak D, Novelline RA, Lawrason JN, Ptak T, Rhea JT, Sacknoff R. Should an MR scan be performed routinely after a normal clearance CT scan in the trauma patient? Experience with 59 cases. Emerg Radiol 2001;8:276-278

38. "The Hippocratic Oath." National Institutes of Health. Available at http://www.nlm.nih.gov/hmd/greek/greek_oath.html 


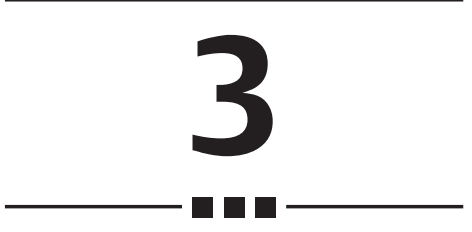

\title{
Type II Odontoid Fractures: Operative versus Nonoperative Management
}

\author{
ANDREW J. SCHOENFELD AND CHRISTOPHER M. BONO
}

Odontoid fractures have posed a challenge to spine surgeons since they were first recognized in the early twentieth century. ${ }^{1}$ The incidence of odontoid process fractures has increased substantially within recent years, with current estimations indicating that they account for up to $15 \%$ of all cervical spine injuries. ${ }^{2,3}$ Odontoid fractures are traditionally classified using the system described by Anderson and D'Alonzo, ${ }^{4}$ with type II fractures (which occur at the waist of the odontoid process) found to be most common (Fig. 3.1) ${ }^{2,3,5,6}$ Unfortunately, type II odontoid injuries are often unstable and have a predisposition toward displacement and nonunion, especially in the geriatric population.

Odontoid fractures occur most commonly as the result of falls or motor vehicle accidents and present in a bimodal age distribution in young adults and elderly patients. . $^{2,3,5,7} \mathrm{In}$ the elderly, odontoid fractures represent the most common cervical injury in patients over the age of 70 years. These injuries are also the most common overall spine fracture in individuals over 80 years. Furthermore, as the North American population continues to age, the incidence of such fractures is predicted to increase. Historically, $50 \%$ mortality rates for odontoid fractures have been reported in the past, though modern advances in diagnosis and treatment have reduced the general rate to 4 to $11 \%{ }^{8}$

The mechanism of injury differs among the two bimodal groups most affected. In young patients, the injury is usually the result of high-energy trauma. In the elderly, the mechanism is typically a low-energy fall. Each presents a unique set of challenges to the treating spine surgeon. Younger individuals with odontoid fractures often present with associated injuries that complicate their care. Elderly patients are more likely to present with an isolated fracture, but medical comorbidities and lower functional reserves adversely impact outcomes. These disparate factors culminate in a relatively high complication rate for both populations, including permanent loss of function and, in some instances, death.
Management options for odontoid fractures have expanded along with advances in imaging and surgical technologies over the last 25 years., ${ }^{3,-10}$ The ideal treatment modality for such injuries, however, has not been established., ${ }^{3,9}$ This may be attributed to the absence of a scientifically rigorous, prospective investigation comparing treatment options. ${ }^{3,7} \mathrm{Ad}-$ ditionally, it is difficult to fashion uniform treatment recommendations based on the current literature, which consists of mostly small, retrospective reports describing outcomes for disparate populations with substantial heterogeneity (Table 3.1).

Potential treatments for patients with odontoid fractures include nonoperative external immobilization in a cervical orthosis, or halo vest, internal fixation via an odontoid screw, or atlantoaxial arthrodesis from a posterior approach. A rigid cervical orthosis can be used to immobilize nondisplaced odontoid fractures and facilitate healing. Due to the high pseudarthrosis rate associated with these injuries, however, many have advocated the use of a halo vest. Halo vest immobilization can also be utilized to maintain alignment in displaced odontoid fractures once they have been reduced.

Posterior C1-C2 arthrodesis may be performed in most instances in which surgical treatment is indicated for odontoid fractures. Historically, a variety of procedures have been performed to effect posterior cervical stabilization. In recent years, the $\mathrm{C} 1$ lateral mass- $\mathrm{C} 2$ isthmus screw technique has gained popularity because it does not require preoperative reduction (as is needed with a $\mathrm{C} 1-\mathrm{C} 2$ transarticular screw) and can be used to intraoperatively reduce odontoid fractures (Fig. 3.2).9,10 Since its description in 1989, the potentially minimally invasive technique of anterior odontoid screw fixation has also gained popularity. ${ }^{11}$ An anterior odontoid screw enables direct osteosynthesis at the fracture site and potentially reduces the limitations associated with loss of head rotation. $2,3,7,9,11$ 


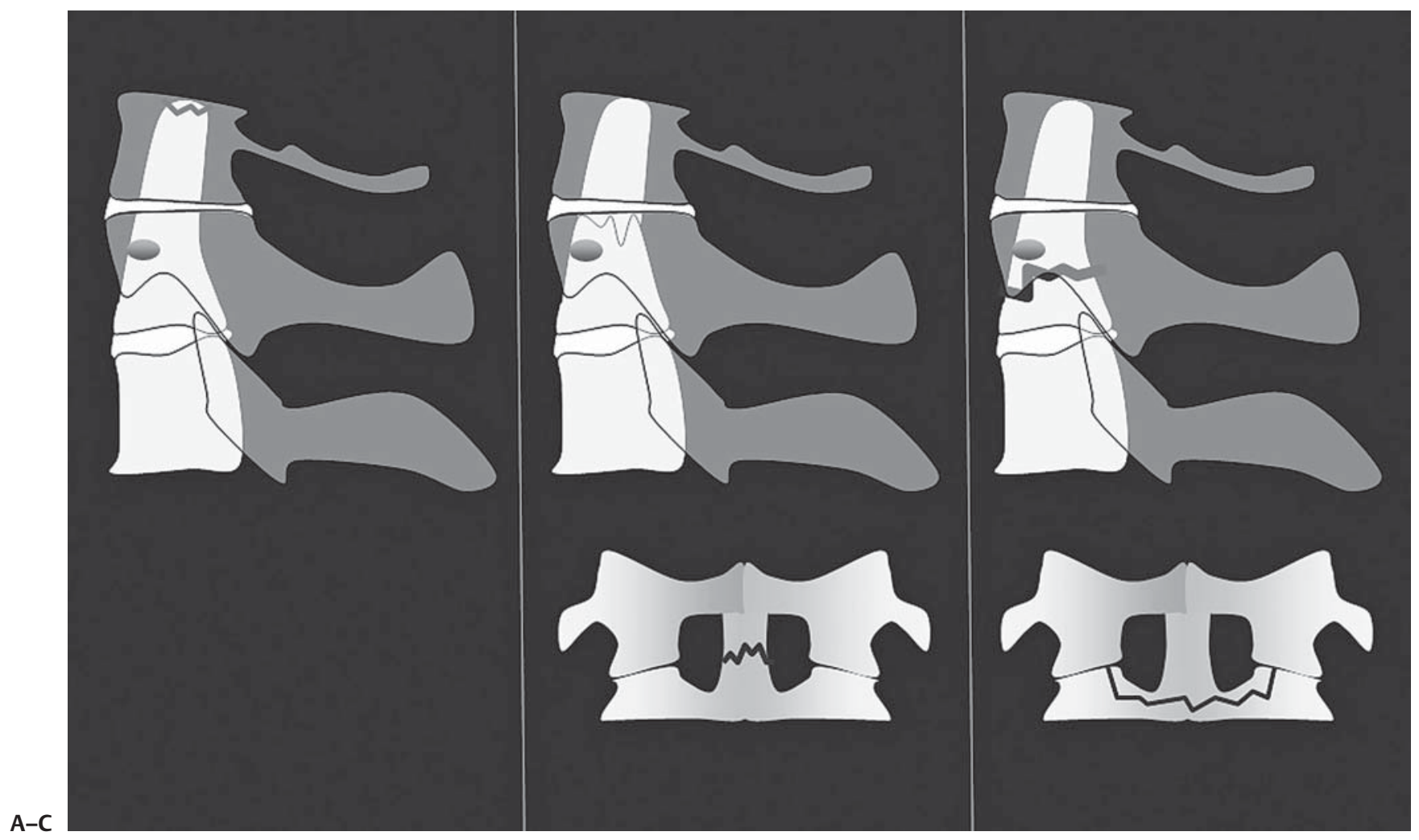

Fig. 3.1 The Anderson and D'Alonzo classification system for odontoid fractures. (A) Type I fractures are avulsions off the odontoid tip, while types II and III fractures represent fractures at the (B) waist of the odontoid and (C) C2 vertebral body, respectively.

In terms of indications and optimal patient selection, however, most management options have been incompletely characterized, particularly in regard to the elderly. At the present time, the optimal treatment for these injuries remains controversial, and recommendations continue to evolve within the context and limitations of published reports. Specifically, controversy still exists regarding the choice of operative versus nonoperative management, the role of halo-vest immobilization, and the merits of anterior screw fixation versus posterior fusion.

Table 3.1 Level of Evidence of Published Studies

\begin{tabular}{lll}
\hline Level & $\begin{array}{l}\text { Number of } \\
\text { Studies }\end{array}$ & Study Type \\
\hline I & 0 & $\begin{array}{c}\text { Prospective, randomized, controlled } \\
\text { trial (0) } \\
\text { III }\end{array}$ \\
& 1 & $\begin{array}{c}\text { Prospective series (1) } \\
\text { Case-controlled } \\
\text { study }(14)^{6,14,15,17-20,24,27,30,31,35-37} \\
\text { Retrospective } \\
\text { series }(11)^{5,11-13,16,23,25,28,32-34} \\
\text { Systematic review }(3)^{7,21,26}\end{array}$ \\
\hline
\end{tabular}

\section{- Operative versus Nonoperative Management}

The level of evidence of comparative studies published in the literature is summarized in Table 3.2.

\section{Level I Evidence}

There is no level I evidence available regarding this topic.

\section{Level II Evidence}

There is no level II evidence available regarding this topic.

\section{Level III Evidence}

There is a variety of level III data evaluating the results of nonoperative management, and comparing outcomes between patients treated conservatively and those receiving surgery. Unfortunately, there are no prospective reports.

Govender et al reported outcomes in 183 patients with odontoid fractures treated solely with external cervical orthoses. ${ }^{12}$ The average age of the patients in this series was 36.7 years, and no patients were over age 65 . Union was achieved in only $54 \%$ of those patients with type II odon- 


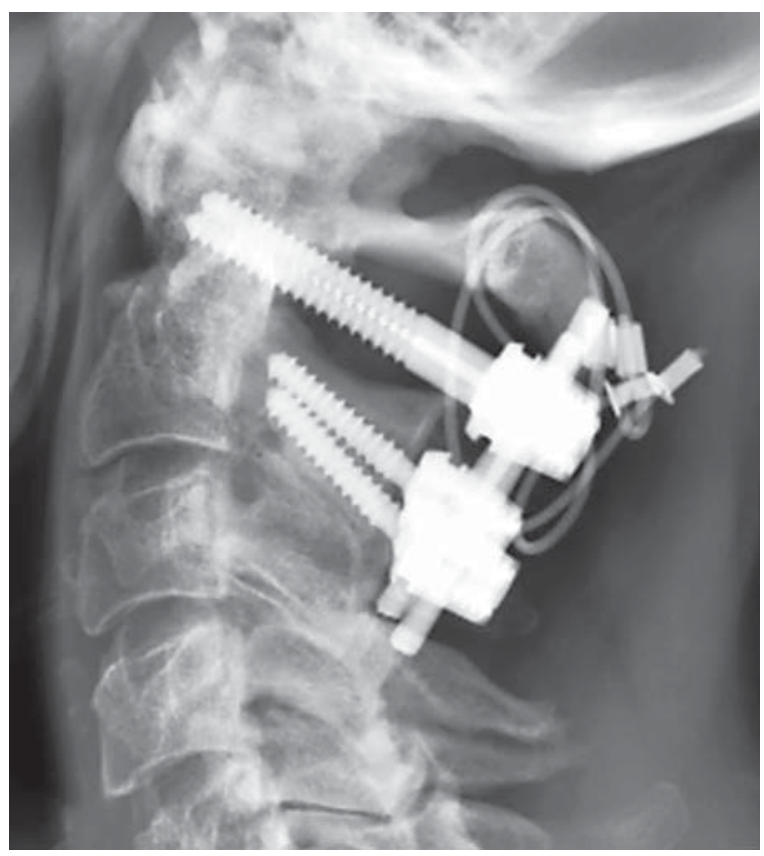

Fig. 3.2 Lateral radiograph of a construct using C1 lateral mass-C2 isthmus screws for reduction and fixation of a posteriorly displaced odontoid fracture.

toid fractures, but the presence of successful healing was not found to have an impact on clinical outcome.

Koech et al examined results in 42 elderly patients (median age of 80) treated conservatively with cervical orthoses or halo-thoracic immobilization. ${ }^{13}$ Radiographic evidence of healing was present in $50 \%$ of patients treated in collars, whereas union was evident in only $37.5 \%$ of those immobilized in a halo-thoracic vest. Once again, radiographic union was not found to correlate with clinical outcome, and the authors affirmed that stability, as detected by flexionextension radiographs, was present in $90 \%$ and $100 \%$ of those treated with cervical collars and halo vests, respectively. ${ }^{13}$
Greene and colleagues reported outcomes for 120 consecutive patients with type II odontoid fractures treated conservatively at a single center. ${ }^{5}$ In this cohort, with an average patient age of 41 , the authors documented a $28 \%$ nonunion rate with conservative management. Comparable rates of healing have also been reported in the conservative treatment arms of several other studies, including those of Ziai and Hurlbert (24\% nonunion rate), ${ }_{1}^{14}$ Clark and White (34\% nonunion rate), ${ }^{15}$ Seybold and Bayley (35\% nonunion rate), ${ }^{6}$ and Hanigan et al (45\% nonunion rate). ${ }^{16}$ It is noteworthy that in the report of Clark and White nonoperative management in a cervical orthosis was found to have no advantage over no treatment. ${ }^{15}$

Several level III studies have also directly compared external immobilization with operative intervention. One of the earliest investigations was that of Clark and White, which investigated outcomes in 96 patients with an average age of 43 years. ${ }^{15}$ These authors found that anterior or posterior surgery resulted in a higher healing rate and fewer complications than immobilization in a halo vest. In this study, successful union was appreciated in $96 \%$ of patients treated surgically compared with $66 \%$ of those treated with halothoracic immobilization.

Seybold and Bayley reviewed outcomes in 37 patients treated with either posterior fusion or external immobilization for the treatment of their type II odontoid fractures. ${ }^{6}$ Complication rates and pain scores were found to be higher and fusion rates lower in those treated with a halo vest. Surgically treated patients also had better functional outcome scores, though not statistically significant except in those patients over the age of 60 years. ${ }^{6}$

Ziai and Hurlbert compared outcomes in 93 patients treated with operative or nonoperative management. ${ }^{14}$ Successful healing occurred in $100 \%$ of those patients who received surgery. Seventy-six percent of those managed nonoperatively went on to heal their fractures, although this value was found to be lower (50\%) in patients over the age of 65. A similar pattern among geriatric patients has

Table 3.2 Summary of Data in Studies Comparing Operative to Nonoperative Interventions

\begin{tabular}{|c|c|c|c|}
\hline Study & Level & Treatment Groups & Conclusions \\
\hline Clark and White ${ }^{15}$ & III & $\begin{array}{l}\text { Surgery (anterior or } \\
\text { posterior) versus } \\
\text { conservative (halo } \\
\text { or collar) }\end{array}$ & $\begin{array}{l}\text { - Successful fusion appreciated in } 96 \% \text { of surgical patients } \\
\text { versus } 66 \% \text { of those treated in a halo. } \\
\text { - Cervical orthosis reported to have no advantage over no } \\
\text { treatment. }\end{array}$ \\
\hline Seybold and Bayley ${ }^{6}$ & III & $\begin{array}{l}\text { Posterior fusion versus } \\
\text { halo }\end{array}$ & $\begin{array}{l}\text { - Higher complication rate, and lower rate of fusion, in the } \\
\text { halo group } \\
\text { - Surgery conferred a better result, especially in patients over } \\
\text { age } 60 \text {. }\end{array}$ \\
\hline Ziai and Hurlbert ${ }^{14}$ & III & $\begin{array}{l}\text { Surgery (anterior or } \\
\text { posterior) versus } \\
\text { cervical collar }\end{array}$ & $\begin{array}{l}\text { - } 100 \% \text { fusion rate for patients treated surgically } \\
\text { - Cervical collar resulted in } 76 \% \text { success rate. } \\
\text { - Only } 50 \% \text { of elderly patients treated in a collar derived a } \\
\text { satisfactory result. }\end{array}$ \\
\hline Shears and Armitstead ${ }^{21}$ & III & $\begin{array}{l}\text { Systematic review of } \\
\text { surgery (anterior } \\
\text { or posterior) versus } \\
\text { conservative (halo } \\
\text { or collar) }\end{array}$ & $\begin{array}{l}\text { - No strong evidence exists to support the notion that surgi- } \\
\text { cal management confers a better outcome on patients. }\end{array}$ \\
\hline
\end{tabular}


been appreciated in other studies as well, ${ }^{16-18}$ with older patients prone to a higher rate of nonunion, complications, and mortality, especially when treated with halo-thoracic vests. ${ }^{19,20}$ Furthermore, a recent investigation has documented a high complication rate as well as increased mortality among elderly patients regardless of intervention. ${ }^{18}$

In an effort to synthesize evidence-based recommendations from the available literature, Shears and Armitstead sought to conduct a systematic review comparing surgery with nonoperative management as treatment for odontoid fractures. ${ }^{21}$ These authors were unable to identify any randomized or prospective investigations addressing the treatment of odontoid fractures. They concluded at the time of their writing that there was no strong evidence that surgical management of odontoid fractures confers a better outcome on patients.

\section{Summary of Data}

Currently no high-level evidence exists to support operative or nonoperative management as the ideal treatment for patients with type II fractures of the odontoid. Based on the limited data available, both external immobilization and operative fixation remain treatment options.,7,12-21 Unfortunately, most investigations comparing operative to nonoperative management have not utilized the most current surgical techniques. Although several studies document a higher fusion rate with surgical fixation, there is limited evidence that the presence of nonunion adversely impacts outcome. ${ }^{6,12}$ Halo fixation may be poorly tolerated in the elderly, with an associated high complication and mortality rate. ${ }^{19,20}$ Nonetheless, poor outcomes have been documented for elderly patients in multiple reports regardless of treatment modality. ${ }^{3,6,16-18}$

\section{Pearls}

- Operative and nonoperative interventions are both viable treatment options for patients with type II odontoid fractures.

- A higher fusion rate can be attained with surgical fixation.

- Complication and mortality rates are higher in elderly patients regardless of intervention.

\section{The Role of Halo-Vest Immobilization}

External immobilization with the use of a halo-thoracic vest is indicated for patients with displaced, or nondisplaced, type II odontoid fractures. ${ }^{22}$ In the event of a displaced fracture, the halo ring can first be utilized to facilitate a traction reduction followed by application of the vest. Halo-thoracic immobilization may be contraindicated in instances where a reduction cannot be obtained or maintained sufficiently utilizing closed techniques. Additionally, the device is also contraindicated in cases of cranial fracture or severe chest trauma. ${ }^{22}$ Nearly all of the evidence for the efficacy of halovest application in the treatment of type II odontoid fractures is level III data.

\section{Level I Evidence}

There is no level I evidence available regarding this topic.

\section{Level II Evidence}

There is no level II evidence available regarding this topic.

\section{Level III Evidence}

Several level III studies have reported outcomes for patients with type II odontoid fractures treated with halo-vest immobilization. In a retrospective review, Platzer et al reported outcomes for 90 patients treated with halo-thoracic vests for odontoid fractures. ${ }^{23}$ The average age of patients in this series was 69 years. Successful healing was documented in $84 \%$ of patients, and $83 \%$ returned to their preinjury activity level. In this study, the risk of nonunion was found to be influenced by patient age at the time of injury, degree of fracture displacement, loss of reduction, and treatment delay. ${ }^{23}$ Comparable high rates of healing have also been reported in the works of Kontautas et al (92\% healing) ${ }^{24}$ and Vieweg and Schultheiss ( $85 \%$ healing). ${ }^{25}$

Despite these findings, however, many reports exist documenting lower success rates for halo-vest immobilization, particularly in elderly individuals. In a review of the literature, Traynelis found a wide variation in terms of the reported success rate for halo-thoracic immobilization. ${ }^{26}$ Overall healing rates varied from 0 to $89 \%$, with an average of $70 \%$.

A recent study from Lennarson et al documented a success rate of $66 \%$ for patients with type II odontoid fractures treated with halo-thoracic vests. ${ }^{27}$ In this investigation, however, the healing rate was found to decrease to $41 \%$ in those individuals over the age of 50 years. Koivikko and colleagues documented a $46 \%$ rate of healing in 69 patients treated with halo vests. ${ }^{28}$ The average age in this series was 57.5 years. Koivikko et al reported that the risk of nonunion was influenced by age greater than 65 years, fracture gap greater than $1 \mathrm{~mm}$, posterior displacement greater than $5 \mathrm{~mm}$, loss of reduction, and treatment delay. ${ }^{28}$

Koech et al documented satisfactory outcomes in a series of 32 elderly patients managed with halothoracic vests. ${ }^{13}$ They demonstrated a $62 \%$ incidence of nonunion, although the lack of healing was not found to correlate with fracture stability and functional results. Tashjian and colleagues documented a $66 \%$ rate of complications and $42 \%$ mortality for elderly patients with odontoid fractures treated in halovests. ${ }^{19}$ In this series, complications included deep venous thrombosis, pulmonary embolism, pneumonia, and cardiac arrest. Similar findings were also documented in the report 
of Majercik et al, who likened halo-vest immobilization in the elderly to a "death sentence." 20

\section{Summary of Data}

No high-level evidence exists to support the use of halo-vest immobilization for the treatment of cervical spine injuries. Numerous level III studies in the literature report satisfactory outcomes among patients treated with halo-vests, although successful healing is documented in an average of $70 \%$ of cases. ${ }^{26}$ Many studies, however, maintain that successful healing does not necessarily correlate with outcome. ${ }^{13,26}$ Degree of displacement, loss of reduction, treatment delay, and advanced patient age have all been found to increase the risk of nonunion. ${ }^{3,13,23,27,28}$ Additionally, complication and mortality rates have been found to increase in elderly patients treated with halo-vest immobilization. ${ }^{19,20}$ Although the literature continues to support the halo-vest as a viable option for patients with nondisplaced type II odontoid fractures, recent data caution against its use in patients over the age of $65.3,13,19,20,23,27,28$

\section{Pearls}

- No high-level evidence exists supporting the use of halo-vest immobilization for type II fractures of the odontoid.

- Fracture displacement, loss of reduction, treatment delay, and advanced patient age have all been shown to increase the risk of poor outcomes with halo use.

\section{Anterior versus Posterior Surgery}

Indications for surgical intervention for odontoid fractures include fracture displacement greater than $5 \mathrm{~mm}$, angulation greater than 10 degrees, and the presence of a neurological deficit., ${ }^{2,3}$ Surgical treatment options consist of direct osteosynthesis with anterior odontoid fixation, or posterior C1-C2 fusion. ${ }^{2,3,7,9}$ Posterior fusion can be utilized in nearly every case of odontoid fracture, whereas odontoid screws are contraindicated in oblique fractures that extend from anteroinferior to posterosuperior.,3,3,9 Odontoid screws may also be contraindicated in instances where a reduction cannot be achieved, in cases of cervical kyphosis, and in individuals whose body habitus (i.e., morbid obesity, or barrel-shaped chest) impedes the necessary trajectory for screw insertion. High-level studies comparing anterior to posterior techniques are lacking, although several level III studies support both anterior and posterior surgical interventions for type II odontoid fractures (Table 3.3).

\section{Level I Evidence}

There is no level I evidence available regarding this topic.

\section{Level II Evidence}

One prospective study investigated outcomes among 11 patients with type II odontoid fractures treated with posterior atlantoaxial fusion using Brooks wiring. ${ }^{29}$ Average follow-up for patients was 1 year with a range of 6 months to 3.5 years. Ten patients successfully healed their odontoid fractures following surgery, whereas one patient went on to nonunion and eventually required anterior odontoid fixation.

\section{Level III Evidence}

Multiple retrospective studies have documented satisfactory healing rates ( 72 to $96 \%$ ) for odontoid fractures treated with anterior odontoid screws. ${ }^{11,30-35}$ The average healing rate for patients in these series was $85 \%$, although success rates are found to be reduced among elderly patients and those with osteoporosis. ${ }^{30,33-36}$ Complication and mortality rates are generally reported to be low for this technique, though higher in the elderly. ${ }^{11,30,33}$

Table 3.3 Summary of Studies Directly Comparing Anterior to Posterior Surgical Techniques

\begin{tabular}{|c|c|c|}
\hline Study & Level & Conclusions \\
\hline Smith et al ${ }^{9}$ & III & $\begin{array}{l}\text { - Posterior fusion associated with increased blood loss } \\
\text { - Anterior odontoid screw increases risk of dysphagia, vocal } \\
\text { cord issues, and pneumonia. }\end{array}$ \\
\hline Andersson et al ${ }^{30}$ & III & $\begin{array}{l}\text { - } 100 \% \text { fusion rate for posterior surgical techniques } \\
\text { - } 28 \% \text { nonunion for anterior odontoid fixation }\end{array}$ \\
\hline Omeis et al ${ }^{36}$ & 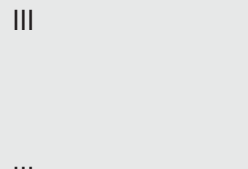 & $\begin{array}{l}\text { - In elderly patients the rate of radiographic union is low for } \\
\text { both techniques. } \\
\text { - Posterior fusion results in greater stability. } \\
\text { - The presence of nonunion does not adversely impact } \\
\text { outcome. }\end{array}$ \\
\hline Julien et $\mathrm{al}^{7}$ & $\begin{array}{l}\text { III } \\
\text { (Review of Level III } \\
\text { Studies) }\end{array}$ & $\begin{array}{l}\text { - The rate of fracture healing is greater with anterior odontoid } \\
\text { fixation. } \\
\text { - The current literature is insufficient and does not permit the } \\
\text { construction of definitive treatment guidelines. }\end{array}$ \\
\hline
\end{tabular}


Several studies have also documented high healing rates (approaching 100\%) for odontoid fractures treated with posterior fusion. 10,29,30,37 Other investigations, however, have reported fusion in $\sim 75 \%$ of patients. ${ }^{7}$ Nonetheless, the success rate for posterior procedures appears to remain high irrespective of patient age, although complications and mortality increase among the elderly. ${ }^{29,37}$ For example, one investigation has documented $20 \%$ mortality for patients over the age of 60 treated with posterior fusion..$^{29}$

Three level III studies have directly compared outcomes among patients with type II odontoid fractures treated with anterior or posterior surgery, ${ }^{9,30,36}$ and one systematic review of the literature has been performed. ${ }^{7}$ Andersson et al investigated healing rates in a series of patients treated with either posterior fusion or anterior odontoid fixation. ${ }^{30}$ One hundred percent of patients treated with posterior fusion healed their fractures, while $28 \%$ of those treated with an anterior screw went on to nonunion.

Smith et al compared outcomes in 75 patients with type II odontoid fractures treated with either anterior or posterior surgical techniques. ${ }^{9}$ The average age of the population in this series was 82 years. Surgical technique was not found to have a significant association with length of hospital stay or mortality. Posterior fusion was associated with a significantly greater blood loss, whereas anterior odontoid fixation was found to carry a significantly greater risk of dysphagia, vocal cord problems, and postoperative pneumonia. ${ }^{9}$ These authors also reported that, at their level-I academic institution, the prevalence of anterior odontoid fixation had diminished in favor of C1 lateral mass-C2 isthmus fixation within the last decade.

A similar investigation was conducted by Omeis et al, albeit in a smaller series of elderly individuals. ${ }^{36}$ In the anterior odontoid screw group, radiographic evidence of union was evident in only $38 \%$ of patients, with $56 \%$ demonstrating stability. The posterior fusion group demonstrated healing in $31 \%$, whereas stability was present in $69 \%$. Nonetheless, radiographic evidence of union and stability was not correlated with outcome because $86 \%$ of patients in this study returned to their previous level of function. ${ }^{36}$

In an effort to compare results based on a meta-analysis of the literature, Julien and coworkers performed a systematic review of the available data. ${ }^{7}$ In this study, all data reviewed was considered to be level III evidence. Although the literature was deemed insufficient to establish treatment guidelines, they concluded that anterior odontoid fixation conferred an advantage in terms of fracture healing when compared with posterior fusion. ${ }^{7}$

\section{Summary of Data}

There is an absence of high-quality research supporting anterior or posterior surgical interventions for type II odontoid fractures. Satisfactory healing rates have been reported for both techniques, although the success rate for anterior odontoid screws may be slightly higher. ${ }^{7}$ Nonetheless, anterior surgical techniques have been associated with a greater risk of airway compromise and postoperative pneumonia. ${ }^{9}$ Additionally, complications and mortality rate have been found to increase in the elderly, regardless of surgical technique, although age and the presence of osteoporosis may have a greater impact on anterior odontoid fixation. ${ }^{30,33,34,36}$ At the present time, both anterior and posterior techniques remain appropriate treatment options, as there is insufficient evidence to support just one approach.

\section{Pearls \\ - Satisfactory healing rates have been reported for both anterior and posterior surgical techniques. \\ - The success rate for anterior odontoid fixation may be higher. \\ - Anterior odontoid fixation carries a greater risk of airway com- promise and postoperative pneumonia.}

\section{- Consensus Statements}

There are no society or study group consensus statements regarding operative or nonoperative intervention, the use of halo-vest immobilization, or anterior versus posterior approaches for the treatment of type II odontoid fractures.

\section{- Conclusions}

There is a paucity of high-quality evidence capable of informing treatment in type II fractures of the odontoid. Based on a comprehensive analysis of the available literature cervical orthoses, halo-vest immobilization, and anterior and posterior surgical techniques are all viable treatment options. Immobilization in a cervical orthosis may be more appropriate for elderly patients or individuals with nondisplaced fractures. Halo-thoracic vests can be utilized for displaced fractures following stable reduction, while surgical intervention is most appropriate in the setting of displaced fractures or neurological compromise. Regardless of treatment modality, however, mortality rates and the incidence of complications can be expected to increase in geriatric patients.

\section{- References}

1. Boehler J. Fractures of the odontoid process. J Trauma 1965;5: 386-391

2. Chutkan NB, King AG, Harris MB. Odontoid fractures: evaluation and management. J Am Acad Orthop Surg 1997;5:199-204

3. Maak TG, Grauer JN. The contemporary treatment of odontoid injuries. Spine (Phila Pa 1976) 2006;31(11, Suppl):S53-S60, discussion $\mathrm{S} 61$

4. Anderson LD, D'Alonzo RT. Fractures of the odontoid process of the axis. J Bone Joint Surg Am 1974;56:1663-1674 
5. Greene KA, Dickman CA, Marciano FF, Drabier JB, Hadley MN, Sonntag VK. Acute axis fractures: analysis of management and outcome in 340 consecutive cases. Spine (Phila Pa 1976) 1997;22:1843-1852

6. Seybold EA, Bayley JC. Functional outcome of surgically and conservatively managed dens fractures. Spine (Phila Pa 1976) 1998;23:1837-1845, discussion 1845-1846

7. Julien TD, Frankel B, Traynelis VC, Ryken TC. Evidence-based analysis of odontoid fracture management. Neurosurg Focus 2000;8:1

8. France JC, Gocke RT. Injuries of the cervicocranium. In: Browner BD, Jupiter JB, Levine AM, Trafton PG, Krettek C, eds. Skeletal Trauma. 4th ed. Philadelphia, PA: Saunders; 2009:813-862

9. Smith HE, Vaccaro AR, Maltenfort M, et al. Trends in surgical management for type II odontoid fracture: 20 years of experience at a regional spinal cord injury center. Orthopedics 2008; 31:650

10. Harms J, Melcher RP. Posterior C1-C2 fusion with polyaxial screw and rod fixation. Spine (Phila Pa 1976) 2001;26:2467-2471

11. Aebi M, Etter C, Coscia M. Fractures of the odontoid process: treatment with anterior screw fixation. Spine (Phila Pa 1976) 1989;14:1065-1070

12. Govender S, Maharaj JF, Haffajee MR. Fractures of the odontoid process. J Bone Joint Surg Br 2000;82:1143-1147

13. Koech F, Ackland HM, Varma DK, Williamson OD, Malham GM. Nonoperative management of type II odontoid fractures in the elderly. Spine (Phila Pa 1976) 2008;33:2881-2886

14. Ziai WC, Hurlbert RJ. A six year review of odontoid fractures: the emerging role of surgical intervention. Can J Neurol Sci 2000;27:297-301

15. Clark CR, White AA III. Fractures of the dens: a multicenter study. J Bone Joint Surg Am 1985;67:1340-1348

16. Hanigan WC, Powell FC, Elwood PW, Henderson JP. Odontoid fractures in elderly patients. J Neurosurg 1993;78:32-35

17. Müller EJ, Wick M, Russe O, Muhr G. Management of odontoid fractures in the elderly. Eur Spine J 1999;8:360-365

18. Smith HE, Kerr SM, Maltenfort M, et al. Early complications of surgical versus conservative treatment of isolated type II odontoid fractures in octogenarians: a retrospective cohort study. J Spinal Disord Tech 2008;21:535-539

19. Tashjian RZ, Majercik S, Biffl WL, Palumbo MA, Cioffi WG. Halovest immobilization increases early morbidity and mortality in elderly odontoid fractures. J Trauma 2006;60:199-203

20. Majercik S, Tashjian RZ, Biffl WL, Harrington DT, Cioffi WG. Halo vest immobilization in the elderly: a death sentence? J Trauma 2005;59:350-356, discussion 356-358

21. Shears E, Armitstead CP. Surgical versus conservative management for odontoid fractures. Cochrane Database Syst Rev 2008;(4, Issue 4):CD005078
22. Bono CM. The halo fixator. J Am Acad Orthop Surg 2007;15: 728-737

23. Platzer P, Thalhammer G, Sarahrudi K, et al. Nonoperative management of odontoid fractures using a halothoracic vest. Neurosurgery 2007;61:522-529, discussion 529-530

24. Kontautas E, Ambrozaitis KV, Spakauskas B, Kalesinskas RJ. The treatment of odontoid fractures with a significant displacement. Medicina (Kaunas) 2005;41:23-29

25. Vieweg U, Schultheiss R. A review of halo vest treatment of upper cervical spine injuries. Arch Orthop Trauma Surg 2001;121:50-55

26. Traynelis VC. Evidence-based management of type II odontoid fractures. Clin Neurosurg 1997;44:41-49

27. Lennarson PJ, Mostafavi H, Traynelis VC, Walters BC. Management of type II dens fractures: a case-control study. Spine (Phila Pa 1976) 2000;25:1234-1237

28. Koivikko MP, Kiuru MJ, Koskinen SK, Myllynen P, Santavirta S, Kivisaari L. Factors associated with nonunion in conservativelytreated type-II fractures of the odontoid process. J Bone Joint Surg Br 2004;86:1146-1151

29. Bednar DA, Parikh J, Hummel J. Management of type II odontoid process fractures in geriatric patients; a prospective study of sequential cohorts with attention to survivorship. J Spinal Disord 1995;8:166-169

30. Andersson S, Rodrigues M, Olerud C. Odontoid fractures: high complication rate associated with anterior screw fixation in the elderly. Eur Spine J 2000;9:56-59

31. Vieweg U, Meyer B, Schramm J. Differential treatment in acute upper cervical spine injuries: a critical review of a singleinstitution series. Surg Neurol 2000;54:203-210, discussion 210-211

32. Fountas KN, Kapsalaki EZ, Karampelas I, et al. Results of longterm follow-up in patients undergoing anterior screw fixation for type II and rostral type III odontoid fractures. Spine (Phila Pa 1976) 2005;30:661-669

33. Henry AD, Bohly J, Grosse A. Fixation of odontoid fractures by an anterior screw. J Bone Joint Surg Br 1999;81:472-477

34. Collins I, Min WK. Anterior screw fixation of type II odontoid fractures in the elderly. J Trauma 2008;65:1083-1087

35. Platzer P, Thalhammer G, Ostermann R, Wieland T, Vécsei V, Gaebler C. Anterior screw fixation of odontoid fractures comparing younger and elderly patients. Spine (Phila Pa 1976) 2007; 32:1714-1720

36. Omeis I, Duggal N, Rubano J, et al. Surgical treatment of C2 fractures in the elderly: a multicenter retrospective analysis. J Spinal Disord Tech 2009;22:91-95

37. Frangen TM, Zilkens C, Muhr G, Schinkel C. Odontoid fractures in the elderly: dorsal C1/C2 fusion is superior to halo-vest immobilization. J Trauma 2007;63:83-89 